\title{
RISK OF HYPOTHERMIA IN A NEW OLYMPIC EVENT: THE 10-KM MARATHON SWIM
}

\author{
Renata R. T. Castro, ${ }^{\mathrm{I}, \mathrm{II}}$ Fernanda SNS Mendes, ${ }^{\text {II }}$ Antonio Claudio L. Nobrega ${ }^{\mathrm{II}}$
}

doi: 10.1590/S1807-59322009000400014

Castro RRT, Mendes FSNS, Nobrega ACL. Risk of hypothermia in a new olympic event: the 10-km marathon swim. Clinics. 2009;64(4):351-6.

INTRODUCTION: There are no available data addressing the potential clinical risks of open-water swimming competitions. OBJECTIVE: Address the risks of hypothermia and hypoglycemia during a 10-km open-water swimming competition in order to alert physicians to the potential dangers of this recently-introduced Olympic event.

METHODS: This was an observational cross-sectional study, conducted during a 10-km open-water event (water temperature $21^{\circ} \mathrm{C}$ ). The highest ranked elite open-water swimmers in Brazil ( 7 men, 5 women; ages $21 \pm 7$ years old) were submitted to anthropometrical measurements on the day before competition. All but one athlete took maltodextrine ad libitum during the competition. Core temperature and capillary glycemia data were obtained before and immediately after the race.

RESULTS: Most athletes (83\%) finished the race with mild to moderate hypothermia (core temperature $<35^{\circ} \mathrm{C}$ ). The body temperature drop was more pronounced in female athletes $\left(4.2 \pm 0.7^{\circ} \mathrm{C}\right.$ vs. male: $\left.2.7 \pm 0.8^{\circ} \mathrm{C} ; \mathrm{p}=0.040\right)$. When data from the athlete who did not take maltodextrine was excluded, capillary glycemia increased among athletes (pre $86.6 \pm 8.9 \mathrm{mg} / \mathrm{dL}$; post $105.5 \pm 26.9 \mathrm{mg} /$ $\mathrm{dL} ; \mathrm{p}=0.014)$. Time to complete the race was inversely related to pre- competition body temperature in men $(\mathrm{r}=-0.802 ; \mathrm{p}=0.030)$, while it was inversely correlated with the change in capillary glycemia in women ( $\mathrm{r}=-0.898 ; \mathrm{p}=0.038)$.

CONCLUSION: Hypothermia may occur during open-water swimming events even in elite athletes competing in relatively warm water. Thus, core temperature must be a chief concern of any physician during an open-water swim event. Capillary glycemia may have positive effects on performance. Further studies that include more athletes in a controlled setting are warranted.

KEYWORDS: Swimming; Athletic performance; Sports; Body temperature changes; Emergency medicine.

\section{INTRODUCTION}

Open-water swimming is defined by the International Swimming Federation (Federation Internationale de Natation (FINA)) as any competition that takes place in rivers, lakes or oceans. ${ }^{1}$ Marathon open-water competitions over $10 \mathrm{~km}$ appeared for the first time as an Olympic event in the Beijing Olympic Games of August 2008.

Although open-water swimming is very popular in countries such as Brazil and Australia, little is known about the specific physiological and medical challenges an athlete

\footnotetext{
${ }^{I}$ Ministry of Health, Exercise Physiology Laboratory, National Institute of Traumatology and Orthopedics - Rio de Janeiro/RJ,Brazil.

"Fluminense Federal University, Department of Physiology and Pharmacology - Rio de Janeiro/RJ,Brazil.

Email: castrorrt@terra.com.br

Tel.: 55213512.4945

Received for publication on November 20, 2008

Accepted for publication on January 25, 2009
}

may undergo during an official competition, and physicians must be prepared to treat potentially unusual medical situations in this competition environment.

There seems to be a common-sense agreement that adequate feeding during an open-water swimming event and the capacity to maintain proper body temperature are the determinants of success in the competition. ${ }^{2}$ Nevertheless, little is known about health issues related to this swimming event, and the few available studies have focused on the effects of swimming in water with very low temperatures and in courses shorter than the official 10-km distance. ${ }^{3,4}$

FINA rules state that the water temperature for official competitions should be higher than $16^{\circ} \mathrm{C}$. This temperature should be checked on the day of the race, two hours before the starting time, in the middle of the course at a depth of $40 \mathrm{~cm} .^{1}$

The unavailability of data regarding the emergency risks of a 10-km open-water swimming competition, along 
with the medical relevance of body hypothermia ${ }^{5}$ and hypoglycemia, prompted us to investigate the effect of this event on body temperature and capillary glycemia in elite swimmers. The hypothesis tested was that body temperature and glycemia would be related to performance in an openwater swimming competition. The results of this study can help doctors and sports organizers prevent serious health hazards and foster the benefits of exercise training and sports competition.

\section{MATERIALS AND METHODS}

This is a case series study describing the effects of an official $10-\mathrm{km}$ open-water swimming competition. The 12 highest-ranked open-water swimmers in Brazil (7 men and 5 women, who have been training for $5 \pm 1$ years) who participated in the final race of the country's 10-km Grand Prix -2006 were invited, and agreed, to participate in the study.

\section{Anthropometric measurements}

On the day before the competition, all athletes were submitted to anthropometric measurements. Body weight was assessed in kilograms using a calibrated scale (to the nearest $0.1 \mathrm{~kg}$ ). Height was measured using a calibrated stadiometer and was recorded in centimeters (to the nearest $0.5 \mathrm{~cm}$ ). Seven skinfold measurements (triceps, subscapular, mid-axilar, suprailiac, abdominal, thigh and calf) were taken on the right side of each swimmer. A skinfold caliper (Cescorf ${ }^{\oplus}$, Brazil), with a precision of $0.1 \mathrm{~mm}$ was used for the measurements of each skinfold, which contained a double layer of both subcutaneous adipose tissue and skin. ${ }^{6}$ Skinfolds were measured three times by an experienced investigator. In addition, girths (relaxed arm, forearm, waist, gluteal, thigh, and calf) and breadths (humerus, femur, and wrist) were measured.

The aforementioned measurements were used to calculate several parameters: the sum of seven (described above) and three (triceps, suprailiac and thigh) skinfolds; body fat percentage, as given by the Faulkner equation ${ }^{7}$ [percent total body fat $=$ (triceps + subscapular + suprailiac + abdominal skinfolds $x 0.153)+5.783$ ]; body surface area, as given by the Dubois \& Dubois equation ${ }^{8}\left[\mathrm{~S}=0.007184 \mathrm{x}\right.$ weight $^{0.425}$ $\mathrm{x}$ height ${ }^{0.725}$; body volume, calculated by the equation $\{$ body volume $=($ weight/100 $) \times$ [percent fat $/ 0.9+100-$ percent fat/1.1] \}; and surface/volume ratio.

\section{Body temperature}

Core temperature was measured on the tympanic membrane immediately before warm-up and within one minute after the athletes got out of the water, using an infrared tympanic thermometer (Digital thermometer TS201, TechLine, Brazil). Measurements were taken after each athlete had dried his or her ear with a towel.

\section{Capillary glycemia}

Capillary glycemia (Accu-Check Advantage, Roche, USA) was measured in all athletes immediately before warm-up and after competition, within three minutes after coming out of the water. There was no restriction regarding the athletes' breakfast or carbohydrate supplementation during the competition.

\section{Statistical analysis}

Analyses were performed in Statistica version 7.0 (Statsoft) Corporation, OK, USA). The normality of continuous data sets was assessed using the KolmogorovSmirnov test. Two-tailed paired t-tests were used to compare pre- and post-event data (data presented as mean $\pm \mathrm{SD}$ ). Differences between the results obtained before and after the competition were represented as deltas. As there were differences between genders (see table 1), bivariate linear correlation coefficients between relevant variables were separately calculated for each gender. Significance was set at $\mathrm{p}<0.05$, and results are presented as mean $\pm \mathrm{SD}$.

\section{Ethical considerations}

All athletes gave informed consent to participate in the study, which was approved by the local ethics committee and followed the principles of the Declaration of Helsinki.

\section{RESULTS}

The water temperature, measured according to FINA rules, ${ }^{1}$ was $21^{\circ} \mathrm{C}$ on the day of the study. The weather was cloudy, with some rainy periods during the race, with an ambient air temperature of $20.1^{\circ} \mathrm{C}$. All athletes completed the race and were wearing full-body swimsuits, with a latex or rubber swim cap. No other protective clothes were used. Anthropometric and competition data for both genders are presented in Table 1.

Using the American Heart Association definition of hypothermia, most athletes finished the race with mild (34$\left.35^{\circ} \mathrm{C} ; \mathrm{n}=3\right)$ to moderate $\left(30-34^{\circ} \mathrm{C} ; \mathrm{n}=7\right)$ hypothermia, as shown in Figure 1. ${ }^{5}$ The difference between post-competition and pre-competition temperatures was greater in female than in male athletes (Table 1). 

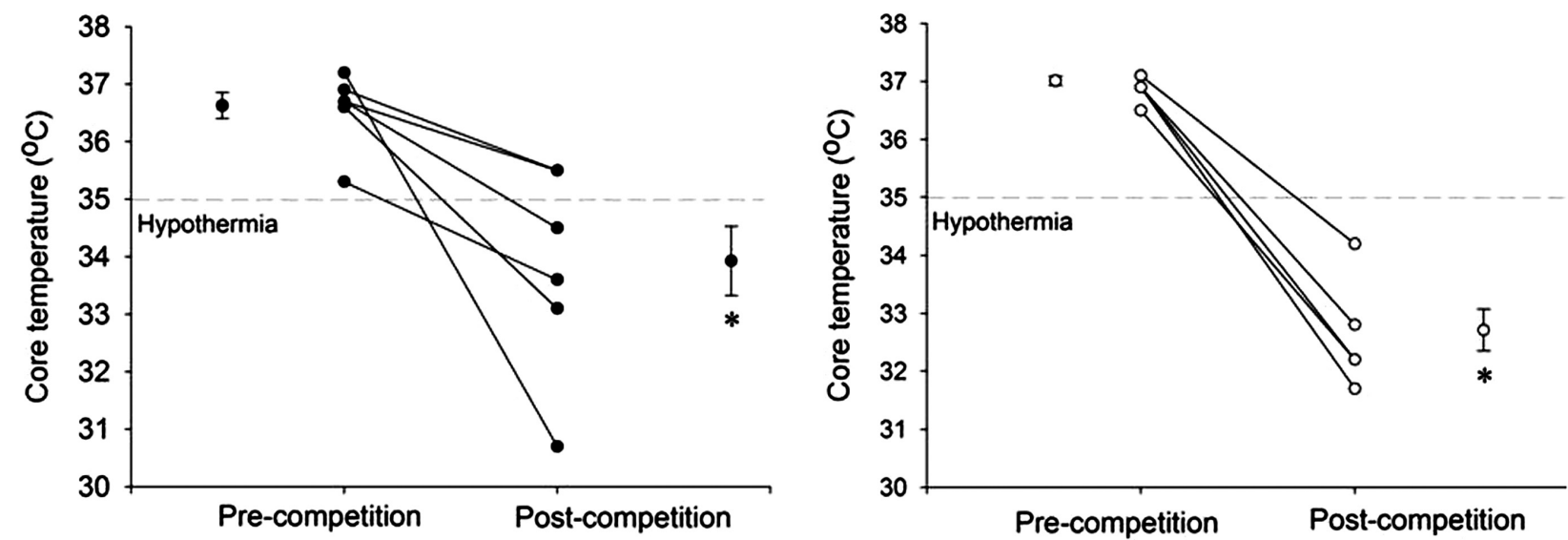

Figure 1 - Individual core temperature of male $(\mathrm{n}=7$; left panel) and female ( $\mathrm{n}=5$; right panel) athletes before and after a 10-km open-water swimming competition. Outer symbols are mean $\pm \mathrm{SE} . * P<0.01$ vs. pre-competition data in the same group. Dotted line shows the limit for hypothermia

Table 1 - Anthropometric and competition data of athletes $(\mathrm{n}=12 ;$ mean $\pm \mathrm{SD})$

\begin{tabular}{lccc}
\hline & Male & Female & $\boldsymbol{P}$ \\
\hline Weight $(\mathrm{kg})$ & $70.1 \pm 8.8$ & $62.6 \pm 4.5$ & 0.044 \\
Height $(\mathrm{cm})$ & $176.1 \pm 8.3$ & $165.0 \pm 6.6$ & 0.014 \\
Sum of three skinfolds $(\mathrm{cm})$ & $28.8 \pm 4.8$ & $61.5 \pm 11.3$ & 0.001 \\
Sum of seven skinfolds $(\mathrm{cm})$ & $73.9 \pm 8.6$ & $137.3 \pm 24.7$ & 0.002 \\
Body fat $(\%)$ & $10.9 \pm 1.1$ & $17.2 \pm 2.4$ & 0.001 \\
Body surface area $\left(\mathrm{m}^{2}\right)$ & $1.9 \pm 0.2$ & $1.7 \pm 0.1$ & 0.020 \\
Surface / volume $\left(\mathrm{x} 10^{3} \mathrm{~m}^{2} / \mathrm{L}\right)$ & $28.6 \pm 1.2$ & $28.6 \pm 1.3$ & 0.497 \\
Time to complete the race & $2: 01: 27 \pm 1: 23$ & $2: 26: 24 \pm 8: 23$ & 0.001 \\
(h:min:s) & & & \\
Delta temperature $\left({ }^{\circ} \mathrm{C}\right)$ & $-2.7 \pm 1.8$ & $-4.2 \pm 0.9$ & 0.040 \\
Delta glycemia $(\mathrm{mg} / \mathrm{dL})$ & $9.7 \pm 15.6$ & $8.6 \pm 59.0$ & 0.484 \\
\hline
\end{tabular}

All athletes received various loads of maltodextrine during the race, with the exception of one athlete who decided to eat a large breakfast and received no supplement during the race. This athlete's glycemia was $161 \mathrm{mg} / \mathrm{dL}$ before the competition and fell to $75 \mathrm{mg} / \mathrm{dL}$ at the end of the race. Capillary glycemia increased as a group when data from this particular athlete was excluded (Figure 2).

In male athletes, total race time was inversely correlated with pre-competition body temperature $(r=-0.802 ; p=0.030$; Table 2), while in female athletes the total race time was inversely correlated with the change in glycemia $(r=-0.898$; $\mathrm{p}=0.038$; Table 3).

\section{DISCUSSION}

Previous studies investigating the impact of an official $10 \mathrm{~km}$ open-water swimming event on the temperature and

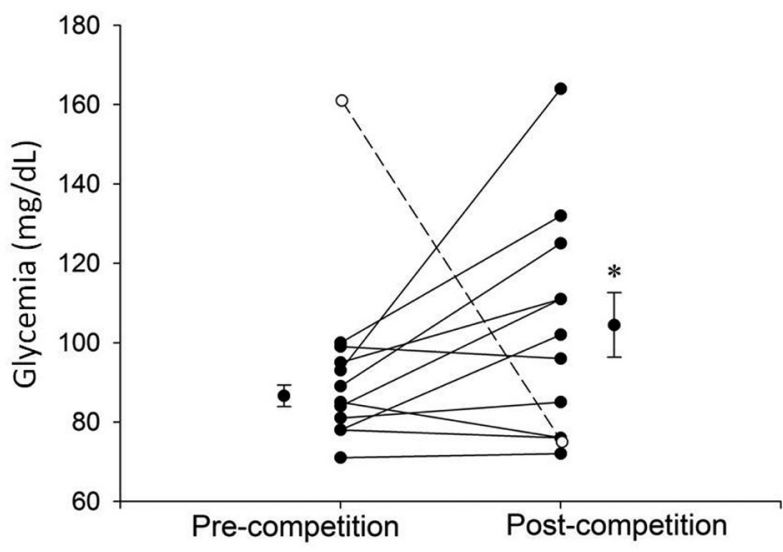

Figure 2 - Capillary glycemia of each athlete before and after a $10-\mathrm{km}$ open-water swimming competition. The white symbol with dashed line shows the only athlete who did not take maltodextrine during the competition. Outer symbols are mean $\pm \mathrm{SE}$ for the other 11 athletes. $* P=0.015$ vs. pre-competition data $(\mathrm{n}=11)$

glycemia of elite marathon swimmers were not found in the literature. Although the present study was performed during a competition in relatively warm water $\left(21^{\circ} \mathrm{C}\right)$, most athletes presented with hypothermia. Hypothermia is a known problem in outdoor sports that are played in cold water. Nuckton et al. studied eleven participants of the Annual New Year's Day Alcatraz Swim in 1998, which is a three-kilometer swim competition in open-water with a temperature of $11.7^{\circ} \mathrm{C} .{ }^{4}$ It seems surprising that only one of the swimmers experienced hypothermia (core temperature $<35^{\circ} \mathrm{C}$ ) in such cold water. Keatinge et al. studied eight Russian athletes who participated in a swim relay of 92 $\mathrm{km}$ in water with a temperature below $11^{\circ} \mathrm{C} .^{3}$ In this type of competition, each athlete decides the duration of his own participation based on perceived exertion and other sensations that may appear during the race. As the water temperature was very low, the mean duration of the swim 
Table 2 - Bivariate linear correlation between anthropometric and performance data among men $(n=7)$

\begin{tabular}{|c|c|c|c|c|c|c|}
\hline & $\begin{array}{c}\text { Body fat } \\
(\%)\end{array}$ & $\begin{array}{l}\text { Body surface } \\
\text { area }\left(\mathrm{m}^{2}\right)\end{array}$ & $\begin{array}{l}\text { Pre-competition } \\
\text { temperature }\left({ }^{\circ} \mathrm{C}\right)\end{array}$ & $\begin{array}{l}\text { Pre-competition } \\
\text { glycemia }(\mathrm{mg} / \mathrm{dL})\end{array}$ & $\begin{array}{l}\text { Time to complete } \\
\text { the race }(\mathrm{s})\end{array}$ & $\begin{array}{c}\text { Delta glycemia } \\
(\mathrm{mg} / \mathrm{dL})\end{array}$ \\
\hline Body fat $(\%)$ & --- & --- & --- & --- & --- & --- \\
\hline Body surface area $\left(\mathrm{m}^{2}\right)$ & 0.59 & --- & --- & --- & --- & --- \\
\hline Pre-competition temperature $\left({ }^{\circ} \mathrm{C}\right)$ & -0.90 & 0.27 & --- & --- & --- & --- \\
\hline Pre-competition glycemia (mg/dL) & 0.16 & 0.44 & 0.22 & --- & --- & --- \\
\hline Time to complete the race (s) & 0.33 & -0.17 & $-0.80^{*}$ & -0.42 & --- & --- \\
\hline Delta glycemia (mg/dL) & -0.44 & -0.01 & 0.30 & 0.34 & -0.72 & --- \\
\hline Delta temperature $\left({ }^{\circ} \mathrm{C}\right)$ & 0.44 & -0.21 & -0.44 & -0.56 & 0.25 & 0.05 \\
\hline
\end{tabular}

$* \mathrm{P}=0.030$

Table 3 - Bivariate linear correlation between anthropometric and performance data among women $(n=5)$

\begin{tabular}{|c|c|c|c|c|c|c|}
\hline & $\begin{array}{c}\text { Body fat } \\
(\%)\end{array}$ & $\begin{array}{l}\text { Body surface } \\
\text { area }\left(\mathrm{m}^{2}\right)\end{array}$ & $\begin{array}{l}\text { Pre-competition } \\
\text { temperature }\left({ }^{\circ} \mathrm{C}\right)\end{array}$ & $\begin{array}{l}\text { Pre-competition } \\
\text { glycemia (mg/dL) }\end{array}$ & $\begin{array}{l}\text { Time to complete } \\
\text { the race }(\mathrm{s})\end{array}$ & $\begin{array}{l}\text { Delta glycemia } \\
\text { (mg/dL) }\end{array}$ \\
\hline Body fat $(\%)$ & --- & --- & --- & --- & --- & --- \\
\hline Body surface area $\left(\mathrm{m}^{2}\right)$ & -0.47 & --- & --- & --- & --- & --- \\
\hline Pre-competition temperature $\left({ }^{\circ} \mathrm{C}\right)$ & -0.16 & -0.86 & --- & --- & --- & --- \\
\hline Pre-competition glycemia (mg/dL) & 0.40 & -0.74 & -0.86 & --- & --- & --- \\
\hline Time to complete the race (s) & -0.11 & -0.38 & -0.78 & 0.67 & --- & --- \\
\hline Delta glycemia(mg/dL) & -0.20 & 0.73 & $0.97 *$ & -0.80 & $-0.89 * *$ & --- \\
\hline Delta temperature $\left({ }^{\circ} \mathrm{C}\right)$ & -0.11 & 0.33 & 0.38 & $0.97 *$ & 0.23 & 0.41 \\
\hline
\end{tabular}

$* \mathrm{P}=0.005 ; * * \mathrm{P}=0.038$

was 53 minutes. Three athletes experienced hypothermia, but none of them presented with core temperatures below $34^{\circ} \mathrm{C}$, suggesting that most athletes were able to judge when it was necessary to leave the water before their core temperature fell to an unacceptable level. In the present study, athletes were exposed to relatively warm water, but for longer periods (at least two hours) than in the previously quoted competitions. Thus, even when the water is warmer than the minimal temperature determined by FINA, medical staff must be aware of the risk of hypothermia in elite swimmers during 10-km open-water competitions.

Most coaches advise that open-water swimmers should have an increased percentage of body fat compared to competitive pool swimmers, as this would be an advantage that allows for better maintenance of body temperature. One study suggested that thinner swimmers were unable to maintain core temperatures above the hypothermia threshold when swimming for long periods in very cold water. ${ }^{3}$ However, no differences in the sum of the skinfolds have been found between American elite open-water athletes and elite pool swimmers. ${ }^{2}$ The athletes in our study have percentages of body fat that are very similar to American open-water swimmers, but there was no relationship between body composition and performance. ${ }^{2}$ Although most athletes presented with hypothermia in the present report, no one has quit the competition prior to finishing it. The controlling mechanisms involved with body temperature, other than body composition, seem to be a key issue related to exercising in a cold environment. Winter swimmers have thermoregulatory functions that differ from non-coldadapted subjects ${ }^{9}$ This better thermoregulatory function is not related to the percentage of body fat of cold-adapted swimmers, but rather to the modified sensory functions of their hypothalamic thermoregulatory centers that lower heat loss and produce less heat during cold exposure. Also, winter swimmers show an increased capacity of non-shivering heat production. ${ }^{9}$ In the present study, body fat was not associated with performance. Alternatively, body temperature appears to have played a role in performance, at least among male athletes, as pre-competition temperature was inversely correlated with time to complete the race.

Finally, there is little doubt that ingesting carbohydrates during prolonged exercise delays fatigue. ${ }^{10}$ In the present study, most athletes maintained, and actually increased, glycemia with carbohydrate supplementation during the race, and hypoglycemia was not an issue. Accordingly, the 
change in glycemia was inversely related to time to complete the race among women, meaning that larger increases in glycemia were related to better performance, and the athlete who presented a fall in glycemia was last among the group.

\section{Limitations of the study}

Most studies that have investigated hypothermia measured rectal temperatures, whereas in the present study core temperature was measured by a tympanic thermometer. Although this makes a direct comparison of absolute values difficult, this technique, which has been previously validated, ${ }^{11}$ can be applied as soon as the athlete finishes the competition and requires no privacy for the measurements to be performed. We should emphasize that this study took place on the beach, and any other technique to measure core temperature would have been impossible to perform. A potential interference in accurate body temperature analysis is that it was measured before the warm-up and thus may not represent the athletes' temperature at the start of the race, since the core temperature could have increased post-warmup to different degrees according to the type, duration and intensity of the warm-up performed. However, it is unlikely that this potential difference would influence the results since warm-up profiles tend to be quite similar among athletes. In addition, athletes completed the warm-up period right before the starting signal, preventing us from measuring body temperature after warm-up.

A recent study ${ }^{12}$ found differences between oral and tympanic temperature measurements taken five minutes after an open-water swimming competition. A more detailed study ${ }^{13}$ found that tympanic thermometers underestimate core temperature by about $1{ }^{\circ} \mathrm{C}$. This information does not invalidate the results of the present study, since such a systematic error would not influence delta temperature results. Additionally, even after adding $1^{\circ} \mathrm{C}$ to the measured temperature of each athlete at the end of the race, seven subjects would still present as hypothermic (core temperature below $35^{\circ} \mathrm{C}$ ).

Although we studied the 12 highest-ranked Brazilian open-water swimmers during an official race, the small sample size may have influenced the results, mainly due to the lack of correlations between measured variables and performance. Another issue is the lack of control of fluid and calorie intake during the competition, since interfering with an athlete's habits during an official competition would be unreasonable.

\section{CONCLUSION}

Hypothermia is a common phenomenon even in elite swimmers competing in relatively warm water temperatures. Therefore, hypothermia could be an important medical concern in open-water swimming events, and measurement of core temperature may be a key concern to physicians during an open-water swim event. Further studies, including a greater number of swimmers in a controlled setting, should be aimed at elucidating the health impacts of this new Olympic event on participating athletes.

\section{ACKNOWLEDGEMENTS}

The authors would like to thank the Brazilian Swimming Confederation for its full support of this study.

\section{REFERENCES}

1. Federation Internationale de Natation. Open-water swimming. In: Federation Internationale de Natation. FINA handbook - Constitution and rules 2005-2009. Lausanne: FINA Office; 2005. p. 146-553.

2. VanHeest JL, Mahoney CE, Herr L. Characteristics of elite open-water swimmers. J Strength Con Res. 2004;18:302-5.

3. Keatinge WR, Khartchenko M, Lando N, Lioutov V. Hypothermia during sports swimming in water below $11^{\circ} \mathrm{C}$. Br J Sports Med. 2001;35:3523.

4. Nuckton TJ, Claman DM, Goldreich D, Wendt FC, Nuckton JG. Hypothermia and afterdrop following open-water swimming: The Alcatraz/ San Francisco Swim Study. Am J Emerg Med. 2000;18:7037.
5. American Heart Association. Hypothermia. Circulation 2005;112: IV136-138.

6. Norton K, Marfell-Jones M, Whittingham N, Carter L, Kerr D. Anthopometric assessment protocols. In: Gore CJ. Physiological tests for elite athletes. Champaign: Human Kinetics; 2000:66-85.

7. Faulkner JA. Physiology of swimming and diving. In: Falls H. Exercise physiology. Baltimore: Academic Press; 1968. p. 415-46.

8. DuBois D, DuBois EF. A formula to estimate the approximate surface area if height and weight be known. Nutrition. 1989;5(5):303-11; discussion 312-3. 
9. Vybiral S, Lesna I, Jansky L, Zeman V. Thermoregulation in winter swimmers and physiological significance of human catecholamine thermogenesis. Exp Physiol 2000; 85:321-6.

10. Murray B. The role of salt and glucose replacement drinks in the marathon. Sports Med. 2007;37:358-60.

11. Jakobsson J, Nilsson A, Carlsson L. Core temperature measured in the auricular canal: comparison between four different tympanic thermometers. Acta Anaesthesiol Scand. 1992;36:819-24.
12. Rogers MB, Branningan D, Montgomery A, Khangure N, Williams $\mathrm{MB}$, Jacobs I. Tympanic thermometry is unsuitable as a screening tool for hypothermia after open water swimming.Wilderness Environ Med. 2007; 18:218-21.

13. Ducharme MB, Frim J. Evaluation of infrared tympanic thermometers on mild hypothermic subjects and in cold environments. Technical report available in http://handle.dtic.mil/100.2/ADA305847. 